\title{
Experiências femininas na carreira da docência superior: entre o cotidiano da "casa" e da profissão
}

Feminine experiences in a higher education teaching career: between the routine of "home" and profession

Neiva Furlin 1

\begin{abstract}
RESUMO
Este artigo analisa narrativas de mulheres (casadas e freiras) que atuam na docência superior em teologia católica, e pretende evidenciar como elas circulam entre a profissão e os trabalhos domésticos, naturalizados como femininos.
\end{abstract}

PALAVRAS-CHAVE: Divisão sexual do trabalho. Docência superior. Desigualdade de gênero. Profissão..

\begin{abstract}
This article analyzes narratives of women (married and nuns) who teach Catholic theology at a college level and aims to show how they circulate between their profession and housework, culturally considered women's work.

KEYWORDS: Sexual division of labor. Higher education teaching. Gender inequality. Profession
\end{abstract}

\section{Introdução}

A entrada das mulheres na formação profissional de nível superior é uma conquista contemporânea que se intensificou a partir das últimas décadas do século XX, sobretudo pela influência das mudanças socioculturais, em grande parte provocadas pelas ações dos movimentos feministas. No Brasil, de acordo com Marareth Rago (1998), o ingresso maciço de mulheres nas universidades ocorreu a partir dos anos de 1970, quando elas passaram a reivindicar o seu espaço na história, assumindo, também, o magistério superior. "A atuação feminina foi ganhando

\footnotetext{
${ }^{1}$ Doutora em Sociologia pela UFPR (2014), com doutorado sanduíche pelo Centro de Investigaciones Interdisciplinarias em Ciencias Y Humanidades (CEIICH) da Universidade Nacional Autónoma de México (UNAM) (2012). Pós-doutoranda no Programa de Pós-graduação em Ciências Sociais, na Universidade Estadual de Maringá. E-mail: nfurlin@yahoo.com.br.
} 
visibilidade, tanto pela simples presença das mulheres nos corredores e nas salas de aula, como pela produção acadêmica que vinha a tona. O mundo acadêmico foi ganhando novos contornos e novas cores". (RAGO, 1998, p. 91).

A crescente escolarização das mulheres possibilitou que elas ingressassem em profissões antes dominadas pelo universo masculino ou que exigiam maior qualificação, como o campo da docência no ensino superior. Nesse sentido, os dados do INEP, referentes ao Censo de 2011, evidenciam que a tendência de crescimento da presença feminina no ensino superior é contínua. Se em 2010 as mulheres representam 44,9\% da docência superior (pública e privada), em 2011 elas já representavam 45\%. Enquanto a participação masculina, durante esse mesmo período teve uma leve redução, ou seja, passou de 55,1\% em 2010 para 55\%, em 20112. Mesmo que a presença masculina continua sendo majoritária, há um processo crescente da participação feminina na docência na Educação Superior.

O Censo Nacional de Docentes do INEP/MEC-2005, apresenta dados da participação por áreas acadêmicas, mostrou que as mulheres continuam mais representadas nas áreas das Ciências Humanas e da Saúde, enquanto que os homens estão mais nas áreas de Ciências Sociais Aplicadas e de Engenharia, o que evidencia uma clara divisão sexual nas carreiras profissionais que historicamente foram construídas como masculinas ou femininas. Isso também é visível dentro da área das humanidades, já que a filosofia e a teologia continuam sendo redutos da docência masculina (FURLIN, 2014) ${ }^{3}$.

É importante enfatizar que a entrada das mulheres no mercado de trabalho alterou de maneira significativa as configurações familiares, embora os estudos mostram uma persistência de certo tradicionalismo nas relações de gênero, no que se refere à divisão do trabalho doméstico. Desse

\footnotetext{
2 Censo da Educação Superior de 2011. Dados disponíveis em:

$<$ http://portal.inep.gov.br/superiorcensosuperior-sinopse>. Acesso em: 16 out. 2013.

${ }^{3}$ Maiores detalhes sobre os dados que sustentam essa afirmação consultar Furlin (2014).
} 
modo, hoje se torna indispensável a necessidade de uma discussão mais profunda em relação as implicações da entrada das mulheres nas atividades profissionais e a organização e distribuição do trabalho no âmbito doméstico, que sendo essencial para a manutenção da vida das pessoas deveria ser responsabilidade de todos. Contudo, a construção feita ao longo da história, em que se naturalizou o trabalho doméstico como obrigação única das mulheres, parece continuar persistindo.

Nesse sentido, Bruschini (1998) tem mencionado que as novas responsabilidades das mulheres não as eximiram dos familiares e maternas. Ao contrário, qualquer que seja sua situação de trabalho, as mulheres ainda seguem sendo as responsáveis por múltiplas tarefas associadas à casa, aos filhos e à família, realizando o que é denominado "ofício doméstico". Em geral, cabe as mulheres o papel de "conciliação" entre a carreira profissional e a família. Para Helena Hirata e Danièle Kergoat (2007), a ideia de conciliação apresenta um conteúdo fortemente sexuado, pois "conciliar" o trabalho e a família é uma responsabilidade creditada frequentemente às mulheres e não aos homens, já que para esses a carreira é pensada sempre de maneira mais independente. Diante de tal constatação, faz-se necessário compreender os aspectos que afetam o cotidiano das docentes que atuam no ensino superior, isso porque ao mesmo tempo em que elas almejam crescer em suas carreiras, em geral, precisam conciliar tais atividades com o cotidiano da vida familiar.

Portanto, este estudo tem como objetivo evidenciar como as mulheres que exercem a docência no ensino superior em teologia católica, em um lugar historicamente masculino, articulam a profissão com os demais trabalhos do cotidiano da vida, que culturalmente são atribuídos e naturalizados como femininos. 
Vale lembrar que as instituições católicas de ensino superior são mantidas por dioceses e ordens ou congregações religiosas ${ }^{4}$, de modo que os quadros da docência nessas instituições são compostos, em sua maioria, por homens celibatários. Isso, também, porque os cursos de teologia de nível superior, ao longo de muitos séculos, têm se destinado a homens que almejavam exercer funções na hierarquia eclesial. As mulheres tiveram acesso a esses cursos, em maior número, a partir das mudanças que ocorreram na sociedade e no universo eclesial, nas décadas de 1970 e 1980.

Apesar da inserção de mulheres nesse universo de saber a sua presença continua bem reduzida em relação as demais áreas das humanidades. Os dados de uma pesquisa de campo, realizada em 2008, com a participação de 56 instituições católicas, que possuíam a graduação em teologia, localizadas em diferentes regiões do Brasil, evidenciaram que de um total de 792 docentes, 671 eram homens (84,7\%) e 121 eram mulheres $(15,3 \%)$. Ou seja, a diferença entre a docência masculina e feminina era de 71,2 pontos percentuais (FURLIN, 2011; 2014). Considerando essa supremacia masculina, tanto na representatividade como nas práticas simbólicas de gênero, presente nas instituições teológicas, as poucas mulheres que ingressaram na docência, mesmo que tenham alcançado altos níveis de formação profissional, precisam empreender maiores energias, tanto em termos de produção acadêmica como em eficiência profissional, para permanecerem nesse espaço (FURLIN, 2014). Desse modo, se torna relevante analisar as experiências contidas nas narrativas das docentes para compreender como elas circulam entre as atividades da docência (ensino e produção acadêmica) e as exigências do espaço familiar ou da vida em comunidade ${ }^{5}$, das que são religiosas ${ }^{6}$.

\footnotetext{
${ }^{4}$ As ordens e congregações religiosas católicas existem desde primeiros séculos da Era Cristã. São diversas organizações de homens e mulheres, leigos e clérigos consagrados, dedicados às mais diferentes atividades pastorais e religiosas.

${ }^{5}$ Usarei o termo religiosas para as mulheres, que popularmente são conhecidas como freiras, porque esse termo é o mais recorrente no interior das congregações ou instituições religiosas.

${ }^{6}$ Adotamos a perspectiva da interpretação hermenêutica segundo os pressupostos teóricos de Gadamer (1999) e de Minayo (2003).
} 


\section{Pressupostos teórico-metodológicos}

Este estudo é realizado segundo a abordagem da pesquisa qualitativa, com foco na interpretação hermenêutica 7 dos relatos apreendidos por meio da entrevista de 12 docentes, inseridas em três instituições católicas de ensino superior ${ }^{8}$. Os critérios para a seleção das interlocutoras foram: ter formação na área da teologia; ministrar aulas no curso de graduação em Teologia 9 ; ter produção acadêmica na perspectiva feminista ou de gênero ou ter tido algum contato com as teorias de gênero e do feminismo durante o processo de formação acadêmica; ser professoras de instituições com o curso de Teologia autorizado ou reconhecido pelo MEC, localizadas geograficamente nas regiões Sul e Sudeste do Brasil. Isso porque nessas duas regiões se encontrava a presença mais significativa de docentes que produziram e publicaram artigos e livros com abordagens de gênero e do feminismo ${ }^{10}$. Também porque os dados quantitativos evidenciaram que essas regiões eram as que concentravam, em termos numéricos, o maior número das instituições que ofereciam o curso de Teologia e onde estavam situadas as instituições com maior reconhecimento, em termos acadêmicos. Esses dados podem ser encontrados em Furlin $(2011 ; 2014)^{11}$.

As narrativas das mulheres docentes colocam em cena discursos, saberes e práticas que são parte da história e da experiência vivida nos seus próprios corpos, que contemplam toda a trajetória do seu devir sujeitos femininos, no campo do saber teológico. Contudo, para este artigo priorizo as

\footnotetext{
7 Adotamos a perspectiva da interpretação hermenêutica segundo os pressupostos teóricos de Gadamer (1999) e de Minayo (2003).

${ }^{8} \mathrm{O}$ conjunto das narrativas foi base para um estudo de tese de doutorado e os nomes das docentes são fictícios, observando os princípios éticos de uma pesquisa.

9 Isso porque nas Pontifícias Universidades Católicas existem docentes da área de teologia que ministram disciplinas de cultura religiosa, em diferentes cursos acadêmicos.

${ }^{10}$ Isso não significa que em outras regiões não existiam teólogas que produziam nessa perspectiva. No entanto, as publicações de teólogas, que se autodenominavam feministas, visibilizavam a sua concentração nas regiões Sudeste e Sul.

11 Esses dados podem ser encontrados em Furlin (2011; 2014).
} 
narrativas que trazem conteúdos sobre as experiências das docentes, quando está em questão o ter que conciliar o cotidiano de suas vidas com a profissão acadêmica.

Vale mencionar que as interlocutoras dessa pesquisa, praticamente todas são de classe média e além de professoras, assumiam diversas atividades, inerentes às diferentes posições de sujeitos que ocupavam, seja como mães, esposas, agentes de pastorais ou religiosas. Ou seja, elas configuram o que chamamos de sujeitos múltiplos pela diversidade de experiências que realizam nas distintas posições de sujeito. Além disso, nota-se diferenças específicas que ocorrem na relação intragênero, já que das 12 entrevistadas, 8 eram casadas e 4 eram religiosas. Neste artigo, tomamos algumas narrativas, ou seja, as que são mais representativas em cada grupo e que possibilitam mostrar as especificidades das experiências sobre a forma como conciliam a profissão acadêmica com funções específicas do ambiente familiar ou da instituição religiosa.

Os conteúdos das narrativas das docentes são analisados à luz dos pressupostos teóricos do feminismo e dos estudos de gênero, na perspectiva pós-estruturalista, e do conceito de divisão sexual do trabalho de Hirata e Kergoat (2007). Trata-se, na visão dessas autoras, de um conceito com duas acepções. Isto é, de um lado, tem-se uma acepção sociográfica, em que se estuda a distribuição diferencial de homens e mulheres no mercado de trabalho, nos ofícios e nas profissões, e as variações no tempo e no espaço dessa distribuição; e de outro, se analisa como ela se associa à divisão desigual do trabalho doméstico entre os sexos.

De acordo com Hirata e Kergoat (2007), o conceito de divisão sexual do trabalho está apoiado em dois princípios: a) princípio da separação, ou seja, existe trabalhos de homens (produtivo, público e com valor monetário) e trabalhos de mulheres (reprodutivo, privado e sem valor monetário) b) princípio hierárquico ou de distribuição, em que o trabalho do homem vale mais que o trabalho da mulher. Para as autoras, esses dois princípios estão 
presentes em todas as sociedades e são legitimados pela ideologia naturalista.

As autoras observam que a divisão sexual do trabalho não é uma estrutura fixa e imutável, mas permeada de plasticidade, já que a sua modalidade sofre variações concretas no tempo e no espaço, como já demonstraram vários estudos de antropólogos e historiadores. Assim, tomar a noção de divisão sexual do trabalho é dar ênfase ao caráter multidimensional do trabalho, compreendendo por trabalho, não apenas o profissional, mas também o doméstico, o não remunerado, o informal. (HIRATA, 2002).

No que se refere as relações entre a esfera doméstica e a profissional, Hirata e Kergoat (2007) apresentam quatro modelos diferentes, nos quais se evidencia a reprodução dos papéis sexuados: modelo tradicional, em que se distingue o papel do trabalho doméstico para as mulheres e o papel de provedor para os homens; modelo de conciliação, no qual cabe exclusivamente às mulheres conciliar o trabalho doméstico com o trabalho profissional; modelo de parceria, onde mulher e o homem aparecem como parceiros, dividindo as tarefas domésticas. Nesse modelo, há mais uma relação de igualdade do que de poder. Contudo, as pesquisas não confirmam a atualidade desse modelo, porque nem sempre há uma igual divisão das tarefas domésticas. Por último, o modelo de delegação, no qual o doméstico é delegado a terceiros, realizado por alguém contratado para tal. O modelo da delegação gera uma cadeia polarizada sobre e entre as mulheres, pois as trabalhadoras domésticas terão que conciliar as suas tarefas domésticas, quando não conseguem pagar, ou delegar para outra mulher.

Já as abordagens de gênero permitiram problematizar, desnaturalizar e desconstruir a concepção biologizante, abordando como a diferença sexual e os papeis sociais de gênero tem sido uma construção histórica, como bem demonstraram estudos de muitas feministas, como Joan Scott (1990), Tereza de Lauretis (1994), Rosi Braidotti (2004). 
Tais estudos têm evidenciado que a divisão sexual do trabalho resulta de um processo de construção binária e hierárquica de gênero, que tomou por base as diferenças anatômicas e se legitimou em uma teia de relações de poder, que reproduziram práticas sociais desiguais entre mulheres e homens, no que tange as responsabilidades com os trabalhos reprodutivos.

Levando em conta esses pressupostos teóricos, no ponto que segue, passamos a interpretar as narrativas das docentes sobre as suas experiências entre o cotidiano da "casa" e da profissão. Devido as diferenças entre elas, optamos por apresentar diversos fragmentos de suas narrativas, sem a preocupação de categorizar por temas, de modo que se possa evidenciar as peculiaridades de suas experiências.

\section{1- Entre o cotidiano da casa e da profissão docente: desigualdades, reprodução e negociações}

Nas narrativas das docentes sobre as suas experiências vividas nas diferentes posições de sujeitos, como mães, esposas, religiosas, agentes de pastoral e professoras, elas detalham sentimentos e sentidos construídos, redescobrem as emoções e revelam como afetam e como são afetadas pelos contextos em que estão situadas (YOUNG, 1990). Evidentemente que, devido a diversidade dessas mulheres, a forma como interpretam ou relatam as suas experiências entre o cotidiano da vida familiar ou institucional com a profissão são distintas, hora se aproximam e hora se distanciam. Contudo, as suas experiências aparecem entrelaçadas por dinâmicas de gênero que as colocam numa posição desfavorável, em termos de sobrecarga de trabalho e de níveis de produção acadêmica, uma vez que a tarefa de "conciliar" trabalho profissional e família aparece como responsabilidade das mulheres e não dos homens. Para esses, a carreira em geral é vista de maneira mais independente. Isto é, há evidência que o princípio da separação sexual do trabalho doméstico, seja em grau maior ou menor, ainda opera na organização familiar. 
Nesse sentido, praticamente todas as docentes narram que precisam se "desdobrar" para dar conta das atividades que envolvem o cotidiano da vida familiar, os compromissos pastorais ou da congregação religiosa com as exigências da profissão. Ao fazerem a memória das estratégias que usam para lidar com todas as dimensões da vida, essas professoras, ao mesmo tempo, refletem, recordam e analisam a suas próprias experiências, colocando em cena as dinâmicas que constroem as desigualdades culturais de gênero que, neste caso, favorecem aos homens e sobrecarregam as mulheres com dupla ou tripla jornada de trabalho.

A gente tem que ser igual "bombril, mil e uma utilidades, porque se não for assim, a gente não consegue. Você tem que desenvolver mil coisas ao mesmo tempo. Por exemplo, quando eu estava escrevendo minha tese, também coordenava o curso de Teologia, porque o padre tinha ido para Roma fazer a tese dele. Então eu estava sozinha, coordenando o curso de Teologia e fazendo minha tese. Nesse tempo, a minha filha se casou. Eu tive que arrumar casamento, festa, marido, casa, cozinha, cachorro, papagaio (risos). Então eu não sei como explicar. Eu acho que a gente acaba desenvolvendo uma capacidade de fazer mil coisas ao mesmo tempo. Quando se está digitando aqui, se vai respondendo a outra pessoa que está lá perguntando. Você tá pensando o que você vai fazer para o almoço amanhã, faz uma coisa aqui, faz outra lá. Quer dizer, isso é extremamente desgastante, eu acho. A mulher para poder fazer isso, ela tem que dar conta de tanta coisa e ainda ser tão competente e, isso é assim desgastante demais. Quando o homem faz isso, faz uma coisa de cada vez. Diz: agora trabalhei muito e quero descansar e a mulher depois que ela trabalha o dia inteiro, chega em casa e tem que continuar trabalhando. Eu acho que o único jeito de a gente poder fazer o que gosta é ir se acostumando e desenvolvendo as habilidades para tudo. (Priscila, 60 anos. grifo meu) 
A narrativa de Priscila descreve a sua experiência de um passado recente em relação as dinâmicas da divisão sexual do trabalho. É possível constatar que o modelo da conciliação entre vida familiar e as exigências da profissão, como bem definiu Hirata e Kergoat (2007), é algo que se coloca para as mulheres. No seu relato, nota-se que a capacidade das mulheres de "fazerem muitas coisas ao mesmo tempo", é algo que se impõe culturalmente por dinâmicas sociais de gênero, que elas acabam reproduzindo em suas práticas. Mais do que virtude, aparece como uma situação extremamente cansativa e desgastante, sobretudo porque para elas ainda se exige alto grau de profissionalismo, já que, nesse caso, estão em um espaço que ao longo dos séculos, tem se construído como masculino e celibatário. Isso porque o saber teológico de nível superior tem sido praticamente destinado aos homens vocacionados para o serviço eclesiástico.

O conteúdo da narrativa de Priscila, também deixa evidente que no campo do saber teológico existem relações desiguais de gênero, que parecem ser naturalizadas, uma vez que ao seu colega foi the permitido se liberar para escrever a tese e, ela, estando na mesma situação, como vice coordenadora do curso de teologia, precisou o substituir e continuar com todas as suas atividades, nas diferentes posições de sujeitos que ocupava. Nota-se, claramente, que enquanto os professores homens se focam na questão profissional, as mulheres precisam ser "biônicas", submetendo-se a uma dupla ou tripla jornada de trabalho ou às dinâmicas socioculturais de gênero que as fazem acreditar que elas precisam conciliar tudo, para continuar exercendo a profissão que gostam.

Isabel, uma professora mais nova na carreira da docência e mãe de um filho pequeno, falou conciliar vida familiar, trabalho doméstico e profissão, porque sempre contou com o auxílio do esposo, que também era professor. Teve, ainda, a seu favor uma rede de mulheres que colaboravam, ou seja, quando o filho nasceu contou com ajuda da mãe e da irmã e depois passou a delegar os trabalhos domésticos para uma terceira mulher. $\mathrm{O}$ fato de ser, ao mesmo tempo, profissional, mãe, esposa e estudante de doutorado, 
sua rotina de vida estava sendo cansativa, pois em cada posição de sujeito lhe eram atribuídas obrigações específicas. Em um mesmo dia de trabalho necessitava transitar entre trabalho e o cuidado do filho, que ainda era bebê, e a noite se dedicava aos estudos para cumprir com as exigências de um doutorado em curso. Considerando que, apesar de tantas atividades, era ela quem tinha que dispor de mais tempo para o cuidado do filho, e não o seu marido, mostra que nas relações sociais impera a convenção cultural de gênero que credita às mulheres a responsabilidade maior no cuidado dos filhos.

Contudo, Isabel parece essencializar a "capacidade de fazer muitas coisas ao mesmo tempo", como um atributo universal do universo feminino. Ela justifica isso da seguinte maneira:

Eu li um texto de uma teóloga argentina em que ela fala que a teologia das mulheres é essa teologia que você está lendo ou escrevendo, arrumando a mochila do filho para ir à escola, passando roupa... Então, ela vai fazendo a narrativa e contando o que se passa ao redor. A mulher é aquela que é capaz de fazer muitas coisas ao mesmo tempo, e isso é uma especificidade dela, né, diferente dele que não consegue fazer duas coisas ao mesmo tempo. Por isso que eu acho que a gente consegue conciliar tudo. É lógico se tivesse o tempo só pra isso, seria o ideal, mas como a gente não tem, a gente vai fazendo tudo ao mesmo tempo. (Isabel, 49 anos)

Ao essencializar a capacidade das mulheres fazerem muitas coisas ao mesmo tempo, Isabel não problematiza a construção social da desigualdade de gênero, assumindo isso como seu papel de mulher. No final, sua narrativa apresenta aspectos que revelam que a inserção no mundo acadêmico ocorre em relações desiguais, já que as mulheres são impossibilitadas de dispor de todo tempo para dedicar-se à academia, na mesma proporção que os homens.

Constata-se que para as mulheres culturalmente se sobrepõem outras "obrigações". Elas não só devem ser boas profissionais como também 
precisam cumprir bem as tarefas de mãe e esposa. São essas condições sociais que as levam a "ser capazes de fazer muitas coisas ao mesmo tempo". Trata-se de uma experiência que é compartilhada pelas docentes, já que praticamente todas mencionaram essa questão. Em algumas delas, há a consciência de que isso resulta das convenções socioculturais que se impõem sobre a vida das mulheres. Porém, há também um discurso reiterativo que materializa essas desigualdades nas relações de gênero, sobretudo, quando se naturaliza o fato que o homem só consegue fazer uma coisa de cada vez, enquanto é da "essência" das mulheres fazerem muitas coisas ao mesmo tempo.

Essa prática reiterativa acaba produzindo o efeito de ocultamento das lógicas de gênero, que foram construídas ao longo da história, por uma ordem social masculina. Assim, a "essência" é constituída por meio de um jogo ritualizado de práticas que produziram a aparência de essência interior, ou seja, de essa "especificidade das mulheres", que nada mais é que uma construção sociocultural, efeito de um discurso reiterativo fundado em práticas desiguais de gênero.

Uma das professoras, que alcançou bons níveis de produção acadêmica e que é reconhecida na área da teologia, relata ser uma pessoa privilegiada por ter chegado a ser a profissional que é. Alega que isso só foi possível porque pode contar com uma rede de relações a seu favor, que envolveu desde o apoio do esposo, como também a colaboração de sua mãe, sobretudo quando os filhos eram crianças. Por outro lado, reconhece que em geral as mulheres exercem uma dupla ou tripla jornada de trabalho, independente da identidade dessas mulheres - casadas, pastoras ou religiosas. Outras ainda, "por não dar conta"12, acabam desistindo ainda durante o processo de formação.

\footnotetext{
12 Esse "não dar conta", inclui até o fato de não terem ao seu favor uma rede de relações familiares que colaboram ou por não disporem de recursos financeiros que lhes permite contratar uma pessoa para os trabalhos domésticos.
} 
Para mim a teologia é uma vocação e não simplesmente uma profissão. Então, a gente ou se dedica e se entrega, ou nunca será realmente uma boa teóloga. Então eu acho que para fazer uma opção dessas, você tem que calcular os seus recursos. O fato de eu ter um marido que sempre me apoiou e me ajudou bastante; o fato de ter outra mulher, que é a minha mãe que morava com a gente, ela me ajudava ficando com as crianças e eu saia e ficava despreocupada. Isso me ajudou, assim, acho que foi toda uma comunidade que entrou ai para que eu pudesse seguir esse caminho. Agora eu vejo as colegas e algumas alunas, coitadas! Tem que largar no meio os estudos ou a profissão, porque não estão dando conta. Tem algumas pastoras que sofrem, pois ainda tem a comunidade para atender, como pastoras também tem a família para atender. É tudo em cima dela. [...] A mulher religiosa também tem seus limites. Eu vejo as religiosas levando uma vida dura, tem a profissão, tem as exigências da congregação, tem a vida espiritual, a oração e tal. Ainda, quando chegam em casa tem o povo batendo na porta, sobretudo as que moram em periferia, que estão em comunidades inseridas. Às vezes tem que levar gente para hospital, durante a noite. É muita coisa em cima da gente, enquanto os homens só se dedicam a profissão. Eu vejo, por exemplo, os jesuítas lá de Belo Horizonte, a cada 5 anos eles tem o ano sabático ${ }^{13}$. Por isso eles avançam muito mais nas pesquisas. (Débora, 60 anos).

Débora analisa não só o seu cotidiano, fala também das condições que se impõem para a maioria das mulheres que atuam no seu campo profissional. Demonstra ter consciência das desigualdades culturalmente e socialmente construídas em relação aos papéis sexuais. Assim, em uma cultura em que a divisão sexual do trabalho vinculou as mulheres ao espaço privado, quando elas conquistam o espaço público acabam acumulando as funções do espaço doméstico, porque no imaginário social essas atividades

${ }^{13} \mathrm{O}$ ano sabático se refere ao tempo de 12 messes que estes intelectuais têm garantido no estatuto de sua instituição para o descanso, para fins de fazer cursos ou pesquisas. 
são específicas das mulheres. Esse acúmulo de funções faz com que elas precisem se "desdobrar" para dar conta de tudo e quando não podem contar com a ajuda de "colaboradoras", elas se obrigam a ter que fazer uma escolha que, em geral, é abandonar o estudo ou a profissão. É possível constatar, nas entre linhas da narrativa de Débora, que as condições desiguais que operam no espaço do trabalho reprodutivo se torna desfavorável para as mulheres que atuam no mesmo campo profissional de seus pares homens. Ou seja, elas jamais podem chegar ao mesmo patamar deles, em termos de produção científica, uma vez que as condições de gênero são desiguais para o mundo das mulheres, sejam elas casadas ou membro de uma congregação religiosa.

Já, a docente Rute (67 anos), apesar de afirmar que hoje tem o apoio do esposo, que sente orgulho do seu trabalho, relatou não ter sido tudo tão fácil nas relações, sobretudo quando, além de ser boa profissional, teve que ser eficiente nas "coisas da casa". Ela sintetiza momentos distintos de sua vida e das estratégias que foi construindo no decorrer de trajetória profissional. Para conciliar trabalho e funções domésticas precisou mudar seu estilo, "deixar alguns furos", relativizar certas cobranças dos membros da família e negociar atividades domésticas ${ }^{14}$.

Só Deus sabe o que eu faço para conciliar a vida profissional e a condição de mãe e esposa (risos) e, isso aí, eu não sei te explicar. Porque, realmente o tempo é um só. Mas é complicado. Eu deixo furos, fazer o que! Antigamente eu era muito perfeccionista, hoje eu não sou mais, pois eu faço o que posso. É bem difícil. Aí, quando o pessoal reclama, eu puxo por um lado, puxo para outro, fico meio elástica. Não tem fórmula, cada um tem que ir descobrindo e construindo. Esse negócio do pós-doutorado foi uma experiência incrível. Meu marido tinha acabado de se aposentar, meus filhos estão todos casados, minha mãe morreu. Então eu pensei “é agora

\footnotetext{
14 Das mulheres docentes casadas, atualmente quase todas contam com a colaboração de uma funcionária, enquanto, no início de carreira nem sempre isso foi possível. Mesmo tendo funcionária, nem todas as atividades que se referem ao espaço doméstico são realizadas por essas "colaboradoras".
} 
ou nunca'. Eu senti apoio do marido. Ele tem orgulho, ele acha que é uma coisa maravilhosa. Não foi sempre assim (risos). No momento, eu estou tendo apoio. Antes era muito difícil viajar. Quando eu recebia um convite, ele achava ótimo, mas quando eu tinha que viajar mesmo, ele achava ruim. Às vezes ele diz assim: 'nossa você não liga mais para a casa'. Antes eu ficava culpada, hoje eu já penso, 'será que isso é tão importante assim’! Então deixo de lado. Se ele tem mais tempo do que eu, porque eu tenho que fazer mercado? Então, tem essas coisas assim, que você tem que negociar. A gente vai negociando, dando um jeitinho aqui e dali. É difícil, para a mulher tudo é mais difícil, mas vale a pena, a gente consegue, (risos). (Rute, 67 anos).

Em geral, as mulheres casadas, mais velhas, narraram que tiveram o apoio do marido, o que favoreceu conciliar seu cotidiano com a profissão que exercem. No entanto, esse apoio aparece como algo que foi lentamente negociado e construído por elas, na relação com seus companheiros e em situações familiares distintas. No relato de Rute, nota-se que o poder de negociação ocorreu pela sua resistência às normas de gênero que eram reiteradas pelo esposo, pelas estratégias que foi criando para levar acabo a sua escolha profissional, sem se eximir totalmente das funções do espaço doméstico.

Esses pequenos rompimentos das convenções culturais de gênero, postas para o universo feminino, permitiu Rute acender ao espaço público, na carreira da docência. Indubitavelmente que isso só foi possível porque Rute viveu em um contexto permeado por profundas mudanças socioculturais, de modo que ela e as demais docentes de sua idade, fazem parte do conjunto de mulheres que tiveram maior oportunidade de estudar, acessar a carreira de docente no ensino superior e ir alcançando níveis de formação até o pós-doutorado, inclusive, fora do Brasil. Contudo, essas estratégias foram sendo construídas, sem um rompimento total com as tarefas domésticas, mesmo quando elas delegaram tais funções, isso porque 
a "gestão do trabalho delegado acaba sendo da competência das mulheres" (HIRATA, KERGOAT, 2007, p. 607).

Assim como Rute, o relato da experiência de Madalena (55 anos) ${ }^{15}$ aponta que para exercer a sua profissão no espaço público, nesse caso na teologia, que era um campo de homens celibatários, foi possível com a compreensão e apoio do companheiro. Subjacente a essa compreensão, que lhes garante apoio, parece ser fundamental que elas se mostrem capazes de conciliar as exigências profissionais com as funções do espaço doméstico:

Hoje, o meu marido já acostumou, mas no começo ele reclamava porque ele não entendia muito bem o porquê de eu estar na teologia. Dizia "não vai ser padre, não vai ser madre, fazer teologia para que". Ele não entendia o campo profissional. Só conhecia o espaço da pastoral na Igreja e na paróquia, mas quando ele entendeu o campo profissional, hoje ele já entende que eu preciso me aperfeiçoar, que preciso ir para congresso, que preciso estar fora. Então hoje não tenho mais esse problema, mas já tive. Acho que muitas mulheres hoje desistem por isso. Tem que dar conta de muita coisa em casa e trabalho e não são compreendidas. (Madalena, 55 anos).

É interessante constatar que ao ser perguntadas como elas conciliavam o trabalho profissional com a vida familiar, o apoio do marido aparece como um elemento importante nas experiências dessas mulheres casadas. De certo modo, esse consentimento que elas necessitam de seus pares evidência a permanência das dinâmicas hierárquicas de gênero, na definição dos papéis sexuais, em que o exercício da profissão no espaço público é tido como "algo natural" para o universo masculino. Tais convecções de gênero foram internalizadas por essas mulheres, uma vez que em suas vidas permanece sempre a tensão entre dedicar-se à profissão e "dar conta" das responsabilidades no âmbito familiar, funções essas que

15 Madalena, no momento da pesquisa, também delegava as tarefas domésticas. 
aparecem como se fosse algo "colado" à natureza biológica feminina. Assim, exercer a profissão tendo o apoio do marido soa sempre como um privilégio e não um direito seu, como cidadã.

Outra professora, também casada, narrou sentir-se "privilegiada", porque apesar do marido ser ateu sempre deu apoio a sua escolha, reconhecendo o quanto a teologia e a sua "vida maluca" de pastoral dava sentido à sua vida e lhe fazia feliz. Relata que no início da sua carreira, teve certa facilidade de conciliar as "tarefas de casa" com a profissão, porque trabalhava 20 horas semanais e tinha situações difíceis, sobretudo quando os filhos eram pequenos. Ela narra a sua trajetória, apontando a importância da colaboração do esposo no cuidado dos filhos, sobretudo em momentos especiais, que a permitiu conciliar sua vida familiar com docência, estudos e atividades pastorais. Contudo, essa conciliação ocorre em uma relação de tensão, que traz em cena os papeis de gênero que foram internalizados por Miriam.

Quando meus filhos eram pequenos, eu conciliava as tarefas de casa e de família trabalhando sempre meio período. Só agora que eles saíram, já são adultos, é que passei a trabalhar o período integral. Fins de semana, feriados eu fazia pastoral. Vejo que às vezes eu sacrifico a família, porque o trabalho de Igreja também exige tempo. Quando eu estava no final da dissertação de mestrado, meu marido saiu com os filhos para uma fazenda pra fazer um acampamento, lá no sul, porque eu precisava pegar uma semana, dez dias seguidos para me concentrar. Depois eu me arrependi um pouco, porque a minha filha menor tinha dois anos, né, ainda usava fraldas de noite. Foi duro pra ela, mas isso eu me dei conta depois. Não tinha outro jeito, eu tinha que me concentrar prá fazer a dissertação de mestrado. Foi um tanto difícil pra ele, porque a mais velha tinha 12 anos, estava começando a entrar nessa vida de namoro e, ele tinha que lidar com a mais velha adolescente e com a mais nova de dois anos. Mas foi, principalmente, para ela que pesou que depois 
percebi na adolescência, o quanto.... Alguém sofreu com aquilo. Enfim, são feridas que ficaram e que até hoje a gente vem curando devagarzinho. Agora ela está com 29 anos. Esses são os sacrifícios da vida. É, algumas vezes eu não percebia o quanto isso é importante na vida. Isso também aconteceu quando eu estava estudando na Bélgica, porque lá eu não tinha outros membros da família. Minha filha mais velha nasceu lá e eu tive que colocar uns dias ela na creche, pra terminar a monografia. (Miriam, 66 anos).

No relato de Miriam a conciliação entre a família e profissão é tensa. Nota-se o quanto o dever da maternidade, no que se refere ao cuidado das filhas, aparece internalizado como uma função específica da mulher, mesmo que ela tenha outras atividades profissionais. Isso fica claro na sua expressão "sacrificar a família", e de seu aparente sentimento de "culpa" por não corresponder com um "determinado papel de mãe" presente no imaginário cultural, sobretudo, por não ter ficado próxima das filhas em momentos em que essas "precisavam" de sua presença mais efetiva. No seu caso, ainda que o modelo da parceria ocorra, ao menos em momentos pontuais, em que o marido se dispõe a cuidar das filhas para que ela possa escrever sua dissertação, a internalização das conveç̧ões sociais de gênero, em relação aos papeis sexuais, faz com que Rute não compreenda que isso é uma responsabilidade que cabe também ao seu esposo, como pai. Ao contrário, se culpabiliza duas vezes, por sobrecarregar seu marido e por não exercer uma função que seria sua, como mãe.

$\mathrm{Na}$ ocasião da pesquisa, Miriam atuava em tempo integral no ensino superior e continuava muito envolvida em atividades pastorais ligadas ao $\mathrm{CEBI}^{16} \mathrm{e}$, ainda, realizava voluntariamente assessoria às Comunidades Eclesiais de Base (CEBs). Narrou que, diante de um momento difícil de uma das suas filhas, ela optou por deixar em segundo plano um compromisso

${ }^{16}$ Centro de Estudos Bíblicos. Trata-se de uma entidade ecumênica sem fins lucrativos que reúne cristãos, mulheres e homens especialistas em Bíblia, de diferentes confissões religiosas com o objetivo de promover uma leitura libertadora da Bíblia para comunidades cristãs populares. 
profissional, como uma maneira de compensar as suas ausências na família em tempos passados, mesmo que tal atividade era relevante dentro da rede das relações de trabalho.

Foi quando eu estava viajando para um Encontro Nacional das CEBs, eu já estava no aeroporto, quando meu marido me ligou dizendo que minha filha havia terminado o namoro. Não pensei duas vezes. Retornei para dar apoio a ela, isso porque agora eu precisava estar do lado dela, já que quando ela era criança eu a tive que deixar, muitas vezes, em segundo plano. Difícil, mais eu disse 'tenho que estar lá. Também teve o outro lado, que eu fiquei dando prioridade para o profissional e, então, eu tive aquela certeza, 'agora eu que vou ter que sacrificar o profissional', que era encontro de CEBs, onde faço assessoria voluntária. O pessoal do CEBI ficou decepcionado porque eu ia representar também o CEBI e não fui. (Miriam, 66 anos).

O conteúdo da narrativa de Miriam revela como a cultura, no processo de socialização das mulheres, tem desenvolvido crenças e valores em relação aos papéis de gênero. Essa construção social pautada no princípio de separação dos papéis sexuais no meio familiar faz como que as mulheres sintam, mais do que os homens, o "dever da maternidade" e de marcarem presença efetiva na vida familiar em situações "especiais". Quando impossibilitadas, por conta de suas escolhas profissionais, acabam culpabilizando-se pelas "ausências" em certos momentos da vida da família. Tal questão se coloca, ainda, como um desafio quando as mulheres precisam conciliar a atenção aos membros da família com o campo profissional e os trabalhos pastorais voluntários, cujas atividades, além de lhes dar satisfação pessoal, são importantes no processo da produção de sentido da experiência vivida e na construção de sua própria subjetividade, como afirma essa mesma docente, "eu não seria feliz se não tivesse isso". 
Isso mostra que, mesmo assumindo outras reponsabilidades profissionais e pastorais, as mulheres não se eximem das atividades familiares e maternais, como tem enfatizado Bruschini (1998). Contudo, tal realidade pode ocorrer não só por uma pressão cultural externa, mas porque as próprias mulheres exteriorizam uma cultura já internalizada, como é perceptível na narrativa de Miriam. Pergunta-se porque elas não conseguem se libertar quando a maioria das entrevistadas se assumem feministas em suas abordagens acadêmicas? Como bem assinalou Hirata e kergoat (2007), isso merece um estudo mais aprofundando com a ajuda de abordagens teóricas dos ramos da psicologia.

A narrativa de Raquel (49 anos) apresenta aspectos distintos em relação as demais. Ela relata que o fato de ter assumido uma perspectiva feminista no modo de educar os filhos e estabelecer as relações no meio familiar, foi fundamental para que fosse possível se dedicar à vida profissional em tempo integral. Construiu uma relação em que os filhos e o marido participassem da dinâmica da organização da casa. Fez essa descoberta quando era estudante de Psicologia, por meio da leitura de um livro que abordava o tema da "autoridade, cooperação e autonomia". Assim, no processo de educação dos filhos assumiu como lema da casa "a cooperação". Nesse sentido, a sua narrativa além de ser diferente, apresenta indicações significativas, como se pode ler a seguir.

[...] eu sempre disse assim, 'eu não sou dona de casa'. Nunca permiti que me chamassem de dona da casa, porque quando você é a dona da casa, você tem que dar conta da casa, como dona dela. Então, eu sempre disse 'a casa é nossa'! Ela não tem uma dona (risos). Todos nós moramos aqui; então se a casa é nossa, todos nós sujamos essa casa e porque só uma pessoa vai limpar? Assim, desde muito pequenos os meus filhos foram aprendendo [...]. Nesse sentido, todos nós trabalhávamos na casa. Isso, tanto no manter a casa organizada no dia da faxina como na hora de fazer a comida. Eu nunca fiz 
comida sozinha. Sempre foi com a participação de nós quatro e a gente passou muito anos almoçando juntos. A gente sempre fez comida em casa e todos ajudando, um ia fazendo a salada, outro ia colocando a mesa, outro fazendo.., entendeu? Então, sempre foi assim, com muita cooperação na casa. Eu também não falo: 'ah, meu esposo e meus filhos me ajudam'. Porque se eu disser que eles me ajudam, eu estou dizendo que o trabalho é meu, não é verdade? Eles não estão me ajudando, o trabalho é nosso! Eu até disse isso, acho, mas muito tempo atrás. Quando eu tomei consciência da coisa (risos), eu passei a dizer diferente. Então para ver como a linguagem vai contribuindo na construção de novos modos de pensar, sentir e agir. Isso também na nossa casa apareceu. Então. eles não me ajudavam, nós todos cooperávamos entre nós. Eu não era a dona da casa. Empregada doméstica, eu só tive quando meus filhos eram muito pequeninos e eu trabalhava um turno só e ai precisava de alguém para estar em casa. O não ter mais uma pessoa contratada foi em razão de evitar que alguém fizesse o serviço por eles, que fosse uma mulher que viesse e fosse empregada e fizesse o serviço. 'Não, a casa é nossa, nós sujamos, nós temos que limpar'. Então até hoje é assim. Eles moram em Porto Alegre e eu moro aqui e, eles não têm empregada, até hoje. Eles dão conta de lavar, passar e limpar a casa. Tenho uma filha de 22 anos e um filho de 25 anos e eles moram juntos num apartamento, porque eu e meu esposo saímos de lá para trabalhar aqui. [...] Quando eu chegava em casa do trabalho, meu filho perguntava se a gente queria comer alguma coisa especial, porque ele não tinha lanchado e, ele queria fazer. Ele não ia dizer assim: 'mãe, prepare uma coisa pra mim'. Ele mesmo ia e fazia. Às vezes eu perguntava se ele queria que eu o ajudasse em alguma coisa. Ele dizia não, porque a mãe tem que fazer? Não. [...] Ah, eu sai duas vezes de casa, no período dos estudos. No meu mestrado e no meu doutorado eu passei uma temporada fora, eu fui para Noruega. Na primeira vez que saí, eu fiquei quase 4 meses na Noruega, foi em 2000, quando meus filhos eram menores. Minha 
mãe e meu pai vieram e ficaram na minha casa para dar uma mão . Já em 2005, não mais, porque eles já eram mais velhos. Fiquei 03 meses fora, foi tranquilo, e não teve essa coisa 'ah, a mãe fora de casa'. [...] Meu marido, tendo uma esposa feminista, ele ganha com isso, só que também ele perde outras mordomias, né (risos). Eu passo a roupa dele, porque ele não gosta de passar, mas ele não tem problema nenhum de fazer comida ou limpar o banheiro. A gente coopera bem um com o outro, não tem essa coisa assim: isso é serviço de homem ou isso é serviço de mulher ou você que cuida da casa, não [...]. Para conciliar, (risos) tem que existir a cooperação de todos. Não é por ser mulher que ela vai deixar de fazer outras coisas fora, porque teria obrigações já dadas. Não, a gente não tem obrigações já dadas e a gente procura ajudar os membros da família para que todos possam fazer aquilo que eles sonham em fazer. Então, a gente procura cooperar um com o outro, uns com os outros. (Raquel, 49 anos).

Raquel estabelece uma espécie de memória reflexiva sobre a sua conduta e se considera feminista também nas ações que realiza no cotidiano de vida. Assim, sua narrativa revela como a consciência feminista possibilita criar uma nova cultura no ambiente familiar que, nesse caso, trata-se da "cultura da cooperação", ou nos termos de Hirata e Kergoat (2007), do paradigma da parceria, que presume a igualdade entre os sexos, em que homens e mulheres se fazem parceiros para conciliar as atividades domésticas e profissionais. Esse paradigma permite ir além do estabelecimento de uma rede de solidariedade e de colaboração de marido, filhos e mães que, de certa forma, mantém a cultura da divisão sexual de tarefas no espaço doméstico.

A narrativa de Raquel sinaliza que o modelo da "cooperação", nas relações cotidianas, pode ser um instrumento importante para desconstruir e ressignificar os papeis sexuais e construir relações igualitárias de gênero, a partir do próprio ambiente familiar. Não se trata apenas de novas 
práticas, mas da proposição de novos conceitos reiterativos no universo da linguagem, como uma maneira de construção ou materialização de práticas mais igualitárias, que superem a lógica da divisão sexual de atividades.

Constata-se, que tanto a reiteração de novos conceitos, como a sua materialização pela prática do modelo de cooperação, no meio familiar de Raquel, vão se reproduzir nas práticas dos próprios filhos, os quais serão gestores de novas práticas culturais em termos de gênero. Isso nos faz corroborar com o pensamento de Lauretis (1994), de que a linguagem e as novas práticas são importantes tecnologias de gênero que modificam mentalidades e, consequentemente, a própria cultura. Ou, no sentido de Butler (2007), pode-se dizer que a citação contínua de um novo conceito, nesse caso o da "cooperação", acaba performatizando as ações que ele nomeia, gerando a possibilidade de novos efeitos ou de novas relações de gênero, nas práticas do cotidiano familiar.

Finalmente, as narrativas das professoras casadas sobre as estratégias utilizadas para conciliar o cotidiano da vida familiar com a profissão da docência, apresentam especificidades que estão vinculadas as próprias experiências, descobertas e relações que essas mulheres estabelecem com os membros da família. Com exceção de Raquel, que apresenta uma prática que favorece a construção de relações igualitárias no ambiente familiar, as outras docentes compartilham de estratégias como: o estabelecimento de redes de colaboração com mulheres, que são suas mães e irmãs ou com seus esposos; a relativização ou mesmo a negociação de certas atividades domésticas e a delegação desse serviço para pessoas contratadas.

Essas estratégias de conciliação não parecem mudar a estrutura da divisão sexual do trabalho, uma vez que a sobrecarga de atividades recai sobre as mulheres, sobretudo, quando elas inconscientemente reproduzem as relações sociais de sexo/gênero. Essa sobreposição de responsabilidades as coloca em um nível desigual no campo profissional, em relação aos seus pares homens, como foi sinalizado em algumas narrativas. Isso porque a estrutura do ensino superior apresenta as mesmas exigências de produção 
acadêmica para ambos os sexos, sem levar em conta as dinâmicas desiguais que se operam no cotidiano de quem é mulher ou homem.

Além disso, considerando que o universo do saber teológico é atravessado por uma estrutura androcêntrica, as exigências que se impõem para as mulheres são maiores, porque a todo o tempo elas precisam de um empenho dobrado para se legitimarem e se constituírem sujeitos femininos de saber teológico, em um campo considerado historicamente como masculino ${ }^{17}$, e ainda ser boa esposa, mãe e cumprir com certos "deveres" considerados culturalmente como seus.

\section{2- A “conciliação" na experiência de mulheres religiosas}

Nas instituições de ensino em teologia católica, como já mencionamos no início deste estudo, a grande maioria dos professores são homens celibatários. Há um número reduzido de mulheres e, entre essas, algumas são religiosas ou conhecidas popularmente como freiras. A situação de sobrecarga de atividades na experiência vivida pelas docentes religiosas não difere das casadas. Talvez, algumas vezes, se intensifica como já assinalou a docente Débora, isso porque há outras dinâmicas que são específicas das congregações religiosas, como vida comunitária, vida de oração, atividades pastorais, além dos trabalhos domésticos.

As quatro professoras religiosas, que participaram da pesquisa, mencionaram ter o apoio da instituição da qual pertencem e das religiosas que integram à sua comunidade. Contudo, afirmam ser difícil conciliar todas as responsabilidades da comunidade religiosa e da instituição, na qual estão vinculadas, com o trabalho pastoral e acadêmico.

A docente Maria (61 anos) narrou conciliar as atividades específicas da vida religiosa com a docência porque sua congregação valoriza muito o seu trabalho na teologia, inclusive a sua perspectiva feminista de reflexão. Por conta disso, tem sido solicitada para escrever artigos e fazer assessorias,

${ }^{17}$ Isso foi evidenciado em um estudo de tese. Detalhes sobre essa questão, consultar Furlin (2014). 
tanto dentro da própria instituição como para outros grupos, em nível de América Latina. São atividades diferentes que acabam lhe conferindo uma sobrecarga de trabalho. Contudo, afirma que algumas vezes não encontrou suficiente abertura na comunidade religiosa para falar sobre seu trabalho. Precisou aos poucos conquistar a confiança de sua instituição, e hoje ela é uma realidade, pois tem recebido várias solicitações para reflexões e assessorias de conteúdos em assembleias anuais de sua própria instituição religiosa. Segundo Maria, essas atividades acabaram pesando, pois se tornaram trabalhos extras, geralmente realizados nos finais de semana. Por isso, muitas vezes precisou do apoio do coordenador do Curso de Teologia para fazer algumas negociações.

Maria interpreta que, apesar da sobrecarga de trabalho, o fato de conseguir conciliar tudo, tem a ver com seu contrato de regime integral, em uma instituição menor, onde é vice coordenadora da graduação, o que lhe permite organizar a sua agenda com as possíveis saídas para as assessorias extras. Aqui, a conciliação tem a ver com a missão do grupo religioso da instituição, em que a docente tem seus vínculos de pertença, e, por isso, precisa dar conta das exigência específicas, como parte de uma missão coletiva. Maria não faz alusão aos trabalhos domésticos porque, em geral, são divididos entre os membros da comunidade religiosa, segundo o modelo de parceria. Isso significa que elas acabam tendo uma tripla jornada de trabalho, já que segundo Maria, as funções solicitadas pela sua instituição são atividades extras, realizadas nos finais de semana.

Ester (51 anos) outra docente, membro da mesma congregação religiosa de Maria, no período da pesquisa estava concluindo sua gestão como membro da equipe da coordenação provincial ${ }^{18}$. No seu relato, ela fala que optou por conciliar as funções da instituição religiosa, sem desvincular-

\footnotetext{
18 A equipe de coordenação de uma instituição religiosa é eleita em assembleia, por um período determinado entre quatro a seis anos. A função dessa equipe é articular, dinamizar e fazer acontecer o planejamento estratégico da referida instituição, acompanhando as atividades missionárias de todos os seus membros, que residem e trabalham em diferentes regiões e cidades do Brasil e, muitas vezes, também em outros países.
} 
se de dois contratos de trabalho, em duas diferentes instituições de ensino teológico ${ }^{19}$. Para isso, disse ter tido o apoio de sua instituição que também lhe disponibilizou, para seu uso pessoal, recursos tecnológicos e o automóvel ${ }^{20}$, visando facilitar o seu trabalho profissional. Contudo, afirmou ser muito cansativo conciliar todas as atividades.

Nossa quase "morri" quando que fui eleita como membro da coordenação provincial, pois foi bem exigente. Embora tendo clareza de minhas atribuições e funções, que seria essa coisa mais de ajudar a pensar, refletir, assessorar, também eu assumi várias coisas. Eu acho que sou privilegiada na minha capacidade de resistência, de me desdobrar. Outra pessoa não conseguiria fazer o que eu fiz e ainda ficar inteira até o fim. [...] Agora, tem uma coisa, que eu acho que é de mulher mesmo, nós temos essa capacidade de fazer várias coisas e, do outro lado, nós que somos da Vida Religiosa e que passamos por um noviciado, a gente aprende essa coisa do ter que se centrar. Eu estou aqui com você, eu estou toda inteira nessa fala. Estando lá, dando aquele curso, e tinha que vim pra cá. Naquele momento que estava com aquele grupo, estou inteira com o grupo e consigo me envolver e isso tem a ver com os processos humanos de cultivo. A Vida Religiosa nos capacita, mas a vida de mulher também nos capacita o tempo todo pra esses desdobramentos. [...] Por outro lado, nós mulheres sempre somos mais sacrificadas, que os homens, por exemplo. Olha, eu estou com uma montanha de roupa lá em casa para lavar. A gente nem se autoriza muito a encaminhar para uma lavanderia. E eu não vou pedir para minha coirmã, que também está sobrecarregada, que nem é tanto assim, mas não quero tê-la como minha... Elas vão ajudar em alguns momentos, mas eu não vou pedir, não vou exigir isso, não tem como.

\footnotetext{
${ }_{19}$ As duas instituições de ensino, em que Ester trabalhava, se localizam na região metropolitana da capital do estado, onde residia. Um dos contratos era de 20 horas aula o outro na coordenação de um programa de formação, na perspectiva do diálogo inter-religioso.

${ }^{20} \mathrm{Em}$ geral nas congregações religiosas femininas, os recursos tecnológicos e motorizados são da instituição e o uso destes recursos é coletivo.
} 
A gente não se autoriza tanto a ter uma pessoa que auxilie. Os homens têm isso tudo garantido, tudo respaldado. Então, de nós tudo se exige, mas a gente nem se permite tanto a buscar outras formas de ajuda. Isso que eu sou uma pessoa muito liberada e vou atrás, crio espaço e busco ajuda, mas também não posso me queixar em termos de respaldo. Comparativamente, eu tive muita compreensão e a minha comunidade religiosa reconhece o meu estar no mundo acadêmico, embora não me libera de umas funções que eu acho que deveria me liberar. As minhas irmãs pedem, cobram ajuda, mas ao mesmo tempo, não veem problema que eu esteja equipada pra fazer coisas. Eu sou a única irmã na Província que tem um carro liberado pra trabalhar. Eu disse 'olha, se vocês acham que pode, tudo bem, se não..., mas apesar disso, eu compartilho o carro com a comunidade e outras podem usar também. Quando eu precisar, eu sei que quando tenho que sair para o trabalho, o carro vai estar sempre ali. Se alguém precisar usar em outro momento, eu mesma faço questão às vezes de fazer o trajeto de ônibus, mas sem o carro não tem como. (Ester, 51 anos)

O conteúdo da narrativa de Ester evidencia que ela concilia atividades distintas vinculada a três instituições, além de sua vida pessoal e comunitária. A estratégia de estar "inteira em tudo o que faz", não parece aliviar a possibilidade de cansaço intelectual. Assim como as docentes casadas, ela vive a experiência de acumular diferentes funções, tendo que se “desdobrar”, para dar conta de tudo. É certo, que nesse caso está em jogo as atividades que lhe são atribuídas pela instituição religiosa e o seu desejo de continuar com a profissão na docência acadêmica. Ao fazer escolha em conciliar todas essas funções certamente a carga de trabalho se triplica. Sua justificativa de que "a vida de mulher também nos capacita o tempo todo para esses desdobramentos", evidencia que Ester compreende que essa capacidade não é algo que vem de uma suposta essência feminina, mas de um aprendizado social e cultural, isto é, das condições sociais que se impõem 
sobre a vida das mulheres. Entretanto, a reiteração contínua desse discurso, que também se constata em outras narrativas, acaba se naturalizado como se fosse um atributo feminino e isso não contribui para a construção de relações igualitárias de gênero.

Na narrativa de Ester é possível constatar certa tensão com condutas e valores internalizados no processo da formação para a Vida Religiosa. Assim, ao mesmo tempo em que teria a necessidade da colaboração nas atividades "mais pessoais", não se permite contar com a ajuda externa. Essa conduta tem a ver com a cultura reproduzida nas instituições religiosas, onde se compartilha valores e práticas que foram internalizadas, numa espécie de consciência coletiva, ou de um habitus, no sentido de Bourdieu (2003), que opera como princípio orientativo para a conduta de quem assume a Vida Religiosa, que é de levar uma vida abnegada, humilde, sem muito luxo ou privilégios. Tais princípios ou valores podem, ainda, ser compreendidos como parte de um discurso de pertença institucional, que constrói uma determinada identidade ou subjetividade religiosa. (FOUCAULT, 2004).

Essa subjetividade religiosa, em Ester, se traduz também na maneira como ela avalia o uso do carro. Afirma, que tem um carro a sua disposição por necessidade e porque a instituição lhe liberou como uma maneira de expressar apoio à sua vida acadêmica. E isso a faz sentir-se privilegiada" por ser a única pessoa da instituição que tem um carro para uso próprio.

Contudo, a sua narrativa deixa entender que não se trata de um privilégio, em relação às demais religiosas da instituição, mas de uma negociação e uma necessidade, já que a própria instituição não a libera de outras funções que requer tempo e preparo $^{21}$. Legalmente ela tem apoio, que se reflete no aparato tecnológico e motorizado, mas por outro lado, a própria instituição aumenta os seus compromissos, porque precisa de sua contribuição e assessoria na perspectiva teológica. Ester se refere ter que

\footnotetext{
${ }^{21}$ Essas outras funções estão no nível de reflexão e assessorias para grupos da própria instituição.
} 
"se desdobrar" para conciliar compromissos em três instituições diferentes, contudo, pouco fala do tempo que ainda necessita para a convivência comunitária e a oração. Isso porque, esses aspectos fazem parte dos princípios que regem a vida religiosa, tido como valores que precisam ser cultivados por parte da pessoa que assume viver esse estilo de vida, vinculado à uma instituição. Assim, a convivência comunitária, a oração e o trabalho profissional, pensado na perspectiva da missão, constituem-se nos três princípios que fundamentam este estilo de vida, e que necessitam de tempo para serem cultivados.

Assim como as professoras casadas, Ester mostra estar consciente da existência das desigualdades de gênero, reproduzidas por dinâmicas sociais e simbólicas, também no universo de homens e mulheres que são padres ou freiras. Isso porque, os professores homens, com vínculos ou não em congregações religiosas, em geral, são liberados para o trabalho acadêmico ${ }^{22}$, o que lhes permite avançar mais em termos de produção. Já as mulheres precisam ou, muitas vezes, escolhem dar conta de "tantas atividades ao mesmo tempo", inclusive de trabalhos na esfera doméstica. Essa mesma lógica não funciona com os homens clérigos, porque a esses é pacífico usufruir da ajuda externa para outras atividades. Esta postura aparece plenamente justificada por discursos e representações sociais que produziram o gênero masculino ${ }^{23}$. (LAURETIS, 1994).

A narrativa da docente Lidia, que também é religiosa, retrata praticamente o quadro acima, mas se torna interessante pela sua especificidade. Lídia concilia os compromissos relacionados à sua opção de vida com um vasto universo profissional, que envolve 20 horas de trabalho

\footnotetext{
22 Convém mencionar que os professores que são de congregações religiosas, muitos deles também dividem compromissos da academia com as responsabilidades da instituição a que pertencem. No entanto, estão mais liberados de algumas atividades, das quais as mulheres geralmente não se liberam, como trabalho doméstico e o cuidado com suas roupas.

${ }^{23}$ Para os homens que pertencem a uma instituição religiosa é quase normal que cada um tenha um carro para uso pessoal e, também naturalmente podem contar com a ajuda externa de mulheres nos afazeres da casa e na lavação de roupa. O que, em geral, é mais raro nas congregações religiosas femininas.
} 
na instituição de teologia, onde além das aulas tem a coordenação do Curso de Teologia Popular, que funciona em várias dioceses e, mais a coordenação de um Centro Social, cuja iniciativa da criação e fundação foi sua. Além disso, ela precisa dispor de tempo para colaborar nos trabalhos domésticos, lavar sua roupa, rezar em comunidade e para realizar outras funções específicas da Vida Religiosa. A sua narrativa chama atenção, porque essa docente expressa o seu cansaço, mas também a escolha pessoal de continuar com todas as atividades.

É bem difícil, conciliar o Centro Social que coordeno, as aulas de teologia, o Curso de Teologia Popular e a Vida Religiosa. É essa loucura que você viu. Marca e desmarca hora para conversar com você. Tem hora que eu penso em largar isso tudo, mas sinto que eu tenho compromisso com isso, porque fui eu que idealizei e fundei esse centro social, há uns cinco anos atrás. Eu comecei na teimosia, comecei um trabalho ali, sozinha, sem apoio da instituição religiosa. Começamos a construir um lugarzinho pequeno, que era mais para fazer a pesagem da Pastoral da Criança. De repente foi dando certo, fui conseguindo apoio, parcerias, consegui convênio na prefeitura, projetos de recursos no exterior. Hoje é um centro social que atende 200 crianças diariamente, com quase 800 refeições por dia, com reforço escolar, oficina de capoeira, teatro, esporte, informática. Tem tudo lá, até escola de família. A gente trabalha com aquelas famílias que tem dificuldades. Dá atendimento personalizado para as mulheres e para as pessoas que precisam. Busca-se proporcionar o empoderamento das educadoras, porque lá são todas educadoras populares, pessoal todo pra estudar; essa coisa toda. Só depois de três anos depois eu ganhei apoio da instituição religiosa, assim, quando a coisa já estava legal. Então, agora nós temos uma comunidade religiosa ali. $\mathrm{Eu}$ invisto muito da minha vida de sábados, domingos e feriados, indo dormindo de madrugada para poder dar conta, né. Por outro, lado eu não tinha planejado em trabalhar com teologia, mas é algo que eu gosto muito e, também, 
penso que posso dar uma contribuição. Então eu vivo nessa corrida, assim tentando conciliar tudo. Por um lado, isso é positivo porque a minha prática ilumina muito a minha vida, ilumina muito a pastoral. Como a gente faz pastoral e eu trabalho na disciplina de pastoral, a gente pode ajudar a repensar essa pastoral eclesial de paróquia, que já não responde e tentar abrir para outros lados, em outros espaços de evangelização de promoção da vida humana, para outras perspectivas. Por outro lado, é um desafio porque sou eu quem lavo minhas roupas, que tenho que ajudar a arrumar a casa, levantar cedo pra rezar, que tenho os compromissos de vida religiosa comunitária e que preciso integrar isso tudo. Então é um desafio, é um conflito, um esgotamento, até stress, né, porque é muita coisa. (Lidia, 39 anos)

O relato de Lidia, deixa evidente, o cotidiano da vida da maioria das mulheres que assumem a Vida Religiosa. Além das atividades pastorais, sociais, ou profissionais, elas compartilham de outras atividades específicas do estado de vida. Em geral, o trabalho doméstico não é delegado, mas é assumido de forma colaborativa, ou no modelo da parceria, no sentido de Hirata e Kergoat (2007), porque todas elas exercem outras atividades externas ou funções da própria instituição.

O conteúdo da narrativa de Lídia, que aborda a sobreposição de diferentes funções, revela que ela se constrói como um sujeito ético, no sentido de Foucault (2007), pautado em valores de resistência, liberdade e reflexividade. Isso se evidencia em duas situações: a) primeiro, porque ela transgride regras institucionais, no sentido de que sem o apoio do seu grupo ela decide colocar em prática o seu desejo de ajudar as crianças carentes, ou seja, ela toma iniciativa por si mesma para criar uma entidade social para esse fim, sem o aval da direção de sua congregação religiosa, como seria o normativo; b) segundo, porque diante da sobrecarga com que se envolveu, até pensa em deixar uma de suas atividades, mas a sua subjetividade religiosa fala mais alto. Sente-se comprometida com o dever ético-religioso 
de continuar com uma obra que promove a dignidade das pessoas, mas também, o dever de continuar lecionando teologia porque avalia, que a sua contribuição é significativa para construir um modelo diferente de evangelização, já que seus alunos, em sua maioria seminaristas, serão os reprodutores das práticas e dos discursos religiosos. No sentido weberiano, pode se dizer que as ações de Lídia são pautadas pela racionalidade com relação à valores e à fins objetivos, como parte de um dever vocacional.

Embora, lecionar teologia, não era inicialmente um projeto para a sua vida, esse espaço junto com as atividades sociais e pastorais se tornaram para Lídia a possibilidade de si, da construção de sua subjetividade religiosa, como se percebe na expressão "isso é positivo porque a minha prática ilumina muito a minha vida, ilumina muito a pastoral". Trata-se de um "sujeito se que subjetiva em sua própria ação" (MINAYO,2003). Lecionar teologia pastoral para Lidia é também um lugar de agência, porque ela afirma que sua experiência prática se torna conteúdo de aula e contribuiu para que os estudantes de teologia repensem a pastoral eclesial das paróquias, abrindo-se para "outros espaços de evangelização e de promoção da vida humana".

Enfim, as narrativas das mulheres religiosas revelam que elas compartilham de uma tríplice jornada de trabalho, uma vez que além da carreira acadêmica e da parceria nos trabalhos de reprodução da vida, no espaço da "casa", elas acumulam ainda outras funções que lhes advêm da missão assumida pelas instituições religiosas, em que estão vinculadas.

\section{À guisa de conclusão}

Para fins de conclusão, consideramos importante apontar alguns aspectos que são relevantes no conjunto do artigo ou que permitem contribuir com o rol das pesquisas que buscam mostrar como as relações de gênero tem se manifestado na esfera do trabalho, das profissões e nas 
relações cotidianas entre mulheres e homens, sobretudo quando está em questão a divisão das responsabilidades no âmbito familiar.

No que se refere as relações entre a esfera doméstica e a profissional, o estudo aponta que o modelo de conciliação entre a carreia acadêmica e as responsabilidades familiares é o que perpassa praticamente todas as experiências das interlocutoras da pesquisa, que são casadas e, quando são religiosas, elas conciliam com as funções próprias desse estilo de vida e com outros compromissos voltados à própria instituição ou à missão na área social e pastoral. Sendo assim, mesmo com algumas diferenças, os resultados da pesquisa indicam certa similaridade entre os dois grupos de docentes na maneira como elas criam estratégias para conciliar o cotidiano com a profissão. Contudo, o tempo de trabalho que é investido em outras funções, para além da academia, é maior na experiência das mulheres religiosas do que nas casadas, já que as últimas, em sua maioria, hoje delegam o trabalho doméstico e as religiosas, em nome dos valores da simplicidade e da austeridade, que é parte do seu ethos religioso, realizam elas mesmas, no modelo de parceria.

Embora se constate certa similaridade nas ocupações e nos processos de gerenciamento do tempo, levando em conta seus contextos e posições identitárias, as docentes criam estratégias distintas para conciliar o cotidiano de suas vidas, no âmbito familiar ou institucional, com a carreira da docência, a qual representa para elas um projeto de construção de si e, também, a possibilidade de contribuir em um campo de saber que ainda é reduto masculino.

Nas experiências narradas por quase todas as docentes, nota-se que elas têm internalizado a cultura que atribui às mulheres a tarefa de conciliar a família com a profissão. Assim, em suas práticas elas reproduzem convenções sociais de gênero, na medida em que se consideram as principais responsáveis pelas funções familiares. Diante de tal realidade, constata-se que há uma inserção desigual no campo profissional do ensino em teologia, já que os homens aparecem mais liberados para as atividades acadêmicas 
enquanto elas precisam dividir seu tempo entre o cotidiano da "casa" e da profissão. Desse modo, o fato dessas docentes "jogarem" em um campo majoritariamente masculino, com forças desiguais, revela o quanto elas se esforçam e se dedicam e, mesmo sobrecarregadas com diferentes atividades, ainda conseguem ser boas profissionais, manter certo nível de produção acadêmica e ocupar lugares de lideranças com eficiência, como foi demostrado em um estudo de tese (FURLIN, 2014). Porém, em condições desiguais de inserção, elas jamais podem chegar ao mesmo nível dos professores homens em termos de produção científica, isso porque as condições de gênero são desiguais para o mundo das mulheres, sejam elas casadas ou membro de uma congregação religiosa.

$\mathrm{Na}$ experiência das docentes, o modelo de conciliação é assumido como um dispositivo de poder ou uma estratégia política que lhes permite se dedicar à profissão que gostam e para garantir o apoio de seus companheiros. Tal postura não ajuda a mudar a estrutura da divisão sexual do trabalho, que associa as atividades domésticas ao universo do feminino. Acaba, sim, fazendo com que as mulheres reproduzam as convenções de gênero que privilegia e libera os homens de sua participação das atividades domésticas.

O estudo aponta que essa sobreposição de responsabilidades que recaem sobre a vida das mulheres as coloca em um nível desigual no campo profissional, em relação aos seus pares homens, como já foi sinalizado. Isso porque, a estrutura do ensino superior apresenta as mesmas exigências de produção acadêmica para ambos os sexos, sem levar em conta as dinâmicas de gênero que se operam no cotidiano de quem é mulher ou homem.

Vale destacar que este estudo foi realizado com professoras que utilizam categorias feministas e conceitos dos estudos de gênero em suas produções acadêmicas, ou que tiveram algum contato com esses conteúdos no período de formação acadêmica. Isso pressupõe que são mulheres que tem algum grau de consciência sobre as desigualdades de gênero que se reproduzem em diferentes cenários sociais, inclusive no âmbito familiar. 
Contudo, impressiona como a maioria das docentes continua atribuindo a si a tarefa de conciliar o trabalho doméstico. Os seus pares aparecem como aqueles que as apoiam na profissão acadêmica e colaboram quando for necessário, ou em situações especificas. Isso nos faz perguntar, como bem pontuou Hirata e Kergoat (2007), porque elas continuam atribuindo a si a responsabilidade maior com a atividades domésticas? De certo modo, isso teria a ver com uma construção social dos papeis sexuais que se naturalizaram a tal ponto que romper com isso se torna um desafio cotidiano que merece esforço, consciência e vigilância psicológica? Perguntas que constituem em problemas de pesquisas que ainda precisam ser investigados.

Apesar dessas contradições, chama atenção a experiência de uma das docentes, que pode levar a vida profissional com mais leveza porque as atividades domésticas se realizavam sob o modelo da "cooperação", que era reiterado como discurso e como prática cotidiana. Essa experiência aponta que a consciência feminista é uma ferramenta fundamental para a construção de relações gênero mais igualitárias no ambiente familiar. Desse modo, a produção de novos conceitos ou conteúdos simbólicos, que fecundam novas práticas sociais, parece ser uma luz que se levanta, ou uma importante estratégia política que possibilita a construção de relações mais igualitárias, capazes de superar a lógica da divisão sexual, que historicamente associou o trabalho doméstico ao universo feminino, como se fosse algo que vem colado à sua natureza biológica.

Faz-se necessário continuar criando outras categorias linguísticas capazes de gerar efeitos ou de materializar novas relações de gênero nas práticas do cotidiano familiar. Nesse sentido, corroboro com Lauretis que os discursos se constituem importantes tecnologias de gênero, que tanto podem reproduzir como construir ou modificar as mentalidades e, consequentemente, a própria cultura.

A construção de relações igualitárias de gênero permanece como um desafio que merece investimento tanto em termos de reflexão como em 
iniciativas concretas, sobretudo quando ainda persiste um imaginário cultural pautado no princípio da separação sexual das atividades domésticas, em que as mulheres, inclusive as que se denominam feministas, continuam se incumbindo da maior parte dos trabalhos no ambiente familiar, seja delegando ou conciliando com as atividades profissionais. Desconstruir a associação do feminino com o espaço doméstico é um processo lento e nada fácil, pois implica em desmontar pressupostos morais, crenças e valores estabelecidos sobre as diferenças entre homens e mulheres. Requer não somente, questionar as representações de gênero tradicionais, onde as diferenças socialmente construídas continuam sendo vistas como naturais, mas também se utilizar da imaginação criativa e da linguagem para produzir um novo simbólico que permita construir novas relações de gênero. Enquanto isso, o nosso papel, como pesquisadores/as, não é só mostrar as continuidades, mas também apontar luzes para a construção de novas práticas, que promovam relações igualitárias entre homens e mulheres, no espaço familiar e profissional.

\section{Referências}

BRAIDOTTI, Rosi. Feminismo, diferencia sexual y subjetividad nómade. Barcelona, España: Editorial Gedisa, 2004.

BRUSCHINI, Cristina. Trabalho feminino no Brasil: novas conquistas ou persistência da discriminação? São Paulo: Fundação Carlos Chagas, 1998.. Disponível em: <http://biblioteca.clacso.edu.ar/ar/libros/lasa98/Bruschini.pdf > Acesso em: 08 jun. 2017.

BUTLER, Judith. Corpos que pesam: sobre os limites discursivos do "sexo". In: LOURO, Guacira Lopes (Org.). O corpo educado: pedagogias da sexualidade. 2.ed. Belo Horizonte: Autêntica, 2007. p.151-172.

FOUCAULT, Michel. A ordem do discurso. 5. ed. São Paulo: Loyola, 1999. A hermenêutica do sujeito. São Paulo: Martins Fontes, 2004. 
História da sexualidade: o cuidado de si. 9. ed. São Paulo: Graal, 2007.

FURLIN, Neiva. Relações de gênero, subjetividades e docência feminina: um estudo a partir do universo do ensino superior em teologia católica. 2014. 386 p. Tese de doutorado do Programa de Pós-graduação em Sociologia da Universidade Federal do Paraná.

Teologia e gênero: a docência feminina em instituições católicas. Revista Eclesiástica Brasileira, n. 284, p.880-910, out. 2011.

GADAMER, Hans-Georg . Verdade e método. Petrópolis:Vozes, 1999.

HIRATA, Helena; KERGOAT, Danièle. Novas configurações da divisão sexual do trabalho. Cadernos de Pesquisa, v. 37, n. 132, set./dez. 2007.

HIRATA, Helena. Nova divisão sexual do trabalho: um olhar voltado para a empresa e a sociedade. São Paulo: Boitempo, 2002.

LAURETIS, Teresa de. A tecnologia de gênero. In: HOLANDA, Eloísa Buarque de (Org.). Tendências e impasses: o feminismo como crítica da cultura. Rio de Janeiro: Rocco, 1994. p. 206-242.

MINAYO, Maria Cecília de Souza de. Hermenêutica-Dialética como caminho do pensamento social. In: MINAYO, Maria Cecília de Souza de: DESLANDES, Suely FERREIRA (Org). Caminhos do pensamento epistemologia e método. Rio de Janeiro: FIOCRUZ, 2003. p. 83-107.

MINISTÉRIO DA EDUCAÇÃO. Indicadores sobre a educação superior no país: Cadastro nacional de docentes 2005. Instituto Nacional de Estudos e Pesquisas Educacionais Anísio Teixeira - INEP / Sistema Nacional de Avaliação da Educação Superior - SINAES. Disponível em: <http://sinaes.inep.gov.br/sinaes/>. Acesso em: 10 out. 2008.

Sinopses Estatísticas da Educação Superior (2010, 2011). Instituto Nacional de Estudos e Pesquisas Educacionais Anísio Teixeira. Disponível em: <http://portal.inep.gov.br/superior-censosuperior-sinopse>. Acesso em: 16 out. 2013. RAGO, Margareth. Descobrindo historicamente o gênero. Cadernos Pagu. Campinas-SP, n.11, p. 89-98, 1998.

SCOTT, Joan W. Gênero: uma categoria útil de análise histórica. Revista Educação e Realidade. Porto Alegre: UFRGS, v.16. n.2, p.5-22, jul/dez.1990. 
WEBER, Max. Sobre algumas categorias da sociologia compreensiva. In: Weber, M. In: Metodologia das ciências sociais. São Paulo: Cortez Unicamp, 1992, parte II. YOUNG, Iris Marion. Throwing like a girl and other essays in feminist philosophy and social theory. Bloomington-Indianápolis: Indiana University Press, 1990.

. Recebido em fevereiro de 2019. Aprovado em abril de 2019. 